\title{
V. Vernadsky: from the geochemistry of technogenesis to the scientific thought of the global society
}

\author{
Liubov Drotianko ${ }^{1}$, Serhii Yahodzinskyi $^{1}$ \\ ${ }^{1}$ National Aviation University, Department of Philosophy, \\ Kosmonavta Komarova ave. 1, Kyiv, Ukraine
}

\begin{abstract}
The paper features the main theses of V. Vernadsky's theory about scientific thought as a global phenomenon. The possibility of the use of the ideas of philosophers-cosmists to understanding the phenomenon of scientific discourse is analyzed. The authors come to the conclusion about the complementarity of the scientific ideas of V. Vernadsky modern approaches to the analysis of science as the driving force of the globalized society.
\end{abstract}

\section{Introduction}

In a globalized society, everybody faces with the need for processing and analyzing of large volume of data in the daily routine. Undoubtedly, the possibility of free and quick access to diverse information, the implementation of innovative technologies and machines, the development of printing and electronic libraries stimulates not only social processes, make them more dynamic, but also gives a chance to the wide audience to express the opinion, participate in discussing topical issues, to influence the decisions. Quite often, this is called the greatest achievement of modern civilization, hallmark of a true democracy, openness and pluralism. However, it is clear that the solution of a more or less important task is impossible without specialists representing different fields of knowledge [1]. Due to this, the specialists who have different methods and methodology, different interpretation of the norms of scientific knowledge, socio-cultural determination of knowledge, different language means etc., are involved into the scientific projects.

As a result, scientists are forced to look for a common communicative field to intensify the integrative processes, to destroy the disciplinary differentiation of science, to transform the criteria of rationality [2, p. 11-13]. In such a way, science gradually turns into a scientific discourse that combines humanities and sciences, coordinates their methodologies, reveals new elements of the socio-cultural environment of science, facilitates the search for universal metalanguage and so on. An analysis of the existing publications in which scientists attempt to identify the phenomenon of scientific discourse, to define the sphere of its action and the limits of its functioning, to fill this concept with meaning, shows that the researchers practically do not use scientific findings made in their country, in particular M. Kholodny, M. Chizhevsky, K. Tsiolkovsky. 


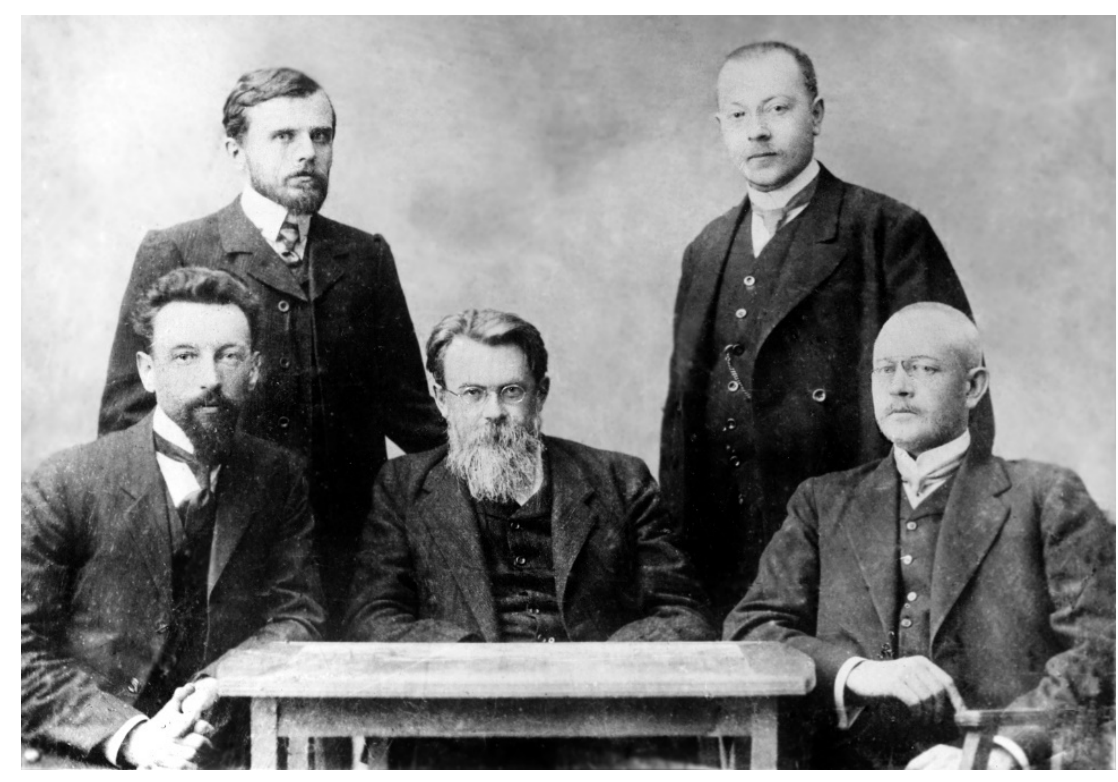

Fig . 1. V. Karandeyev, V. Vernadsky, P. Aleksat are sitting, G. Kasperovich, A. Fersman are standing in the photo. Imperial Moscow University, 1911.

\section{Aim and tasks}

The research mainly concerns the creative heritage of V. Vernadsky [3], who expressed the idea of the all-planetary nature of scientific thought and its direct influence on the processes of co-evolution of nature and man at the beginning of the 20th century.

So, the main purpose of the research - is to establish a correlation between the modern understanding of the nature and causes of the phenomenon of scientific discourse and the Vernadsky's doctrine on the scientific thought as a planetary phenomenon and to discover the possibility of the use of the scientist's ideas to understand the specifics of modern postclassical science.

\section{Research methods}

Since there are enough scientific publications devoted to the work of V. Vernadsky, it is not necessary to reduce the analysis of literature to the comparison of different positions regarding the contribution and the significance of the ideas of the outstanding scientist to the development of science and philosophy. As stated above, there are practically no studies in which the comparison of the concept of scientific discourse and the doctrine of science as a planetary phenomenon was made. We tried to systematize the creative heritage of V. Vernadsky, which could enable us to make a clear distinction between the works, the problematics of which are interesting for this study.

His scientific and philosophical works are usually divided into three sections.

1. The doctrine of the noosphere as a sphere of intelligent human life. ('Biosphere and Noosphere', 'Living matter and the biosphere', 'Scientific thought as a planetary phenomenon'). In this section the concept noosphere was firstly introduced, the essence of the co-evolution of human and nature was substantiated, the definition of science as an allplanetary phenomenon was given, and the influence of human activity on the geological processes was demonstrated. 
2. The analysis of the history of science ('Scientific knowledge; scientific creativity; scientific thought'; 'Philosophical thoughts of the naturalist'; 'Works on the general history of science'; 'Works on the history of science in Russia'). These works offer a rather interesting approach to the study and teaching of the history of science, which can be called socio-cultural $[4,5,6,7,8]$. The thinker suggested not to focus exclusively on the history of scientific discoveries, but pay maximum attention to the identity of scientists, their biography, looking for the true motives for act, including the irrational ones. Today, this position is upheld by more and more representatives of methodology, sociology and psychology of science.

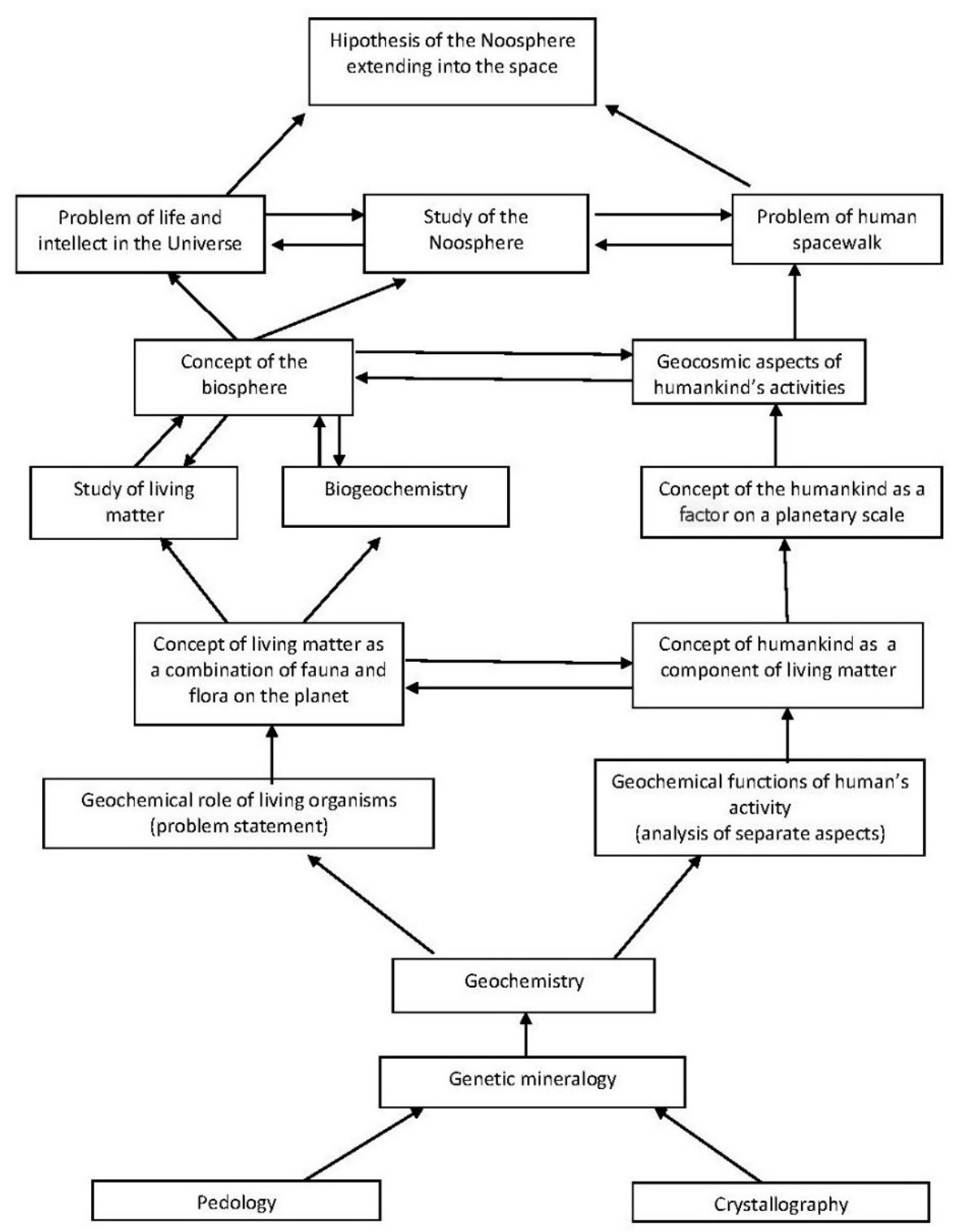

Fig. 2. Bio - and Anthropocosmic concepts of V. Vernadsky [9, p. 188]. 
3. The scientific works on physics, geochemistry, geophysics, mineralogy, biogeochemistry, crystallography ('Essays on Geochemistry', 'The Problems of Biogeochemistry', 'Living matter', etc.). Due to these works V. Vernadsky still remains a great figure in the scientific world. In particular, this is proved by the data about the quotations from his works in scientific publications (mainly in the magazines about the Geosphere, the Biosphere, as well as in mathematical, physical, and geographic magazines), which show that even in spite of a small number of foreign publications, the ideas expressed by the great scientist, are actively disputed and analysed by the scientific companionship.

According to Z. Ivanova and O. Yudenkova 'The main principles, developed by V.I. Vernadsky, include the equality of all races and confessions, the freedom of the scientific thought and scientific research from any pressure produced by religious, philosophical, and political constructs; development of the background promoting the freedom of the scientific thought within the framework of the social structure and political system; higher welfare of the working people' [10, p. 301]. However, it should be mentioned that V. Vernadsky is almost unknown as a methodologist of science, who paid considerable attention to the issues of scientific creativity, the history of science, the development of the scientific thought. Therefore, the scientific work of V. Vernadsky is known and quoted only by some western scholars including L. Margulis, V. Krumbain, P. Westbroeck and some others.

Due to this, numerous attempts are made to include the creative work of the thinker in the world of philosophical thought. For example, V. Shubin compares him with the prominent German philosophers I. Kant and G. Hegel. V. Steopin, L. Kuznetsov, M. Moiseyev and others try to incorporate the doctrine of the noosphere of V. Vernadsky into the philosophy of cosmicism; V. Onoprienko notes that the prominent scientist influenced on the formation of the philosophical position of P. Florensky. I. Shklovsky and V. Kazyutinsky who apply the results of his research to substantiate the essence of the anthropic principle.

Despite the diversity of approaches to the analysis of the philosophical ideas of the scientist, there is no doubt that V. Vernadsky made a significant contribution of to the formation of the methodological consciousness of post-classical science and the whole modern scientific discourse. However, even such a variety of concepts, to the study of which the works of V. Vernadsky are included, does not give us the right to say that he was understood and accepted by our contemporaries. There are several reasons for this. Firstly, it is obvious that a significant part of the scientific discoveries of the scientist has lost its relevance or has been developed in the works of followers. Secondly, the ideas of V. Vernadsky concerning the history and methodology of science, was thrown into the shadow by the creativity of poststructuralists and the representatives of the 'historical school'. Thirdly, the inclusion of V. Vernadsky to the unpopular cosmic philosophy somewhat hindered the study of his legacy in the 60-90-ies of the 20th century. This is confirmed by the first pages of the anthology 'Russian Cosmism', in which the excerpts from the works of the prominent scientists were compiled into one book for the first time at the beginning of the twentieth century. On the basis of their analysis, the idea of a unidirectional position regarding the onset of the 'active-evolutionary stage' of the development of the world and humanity was substantiated [11, p. 3-33].

\section{Research results}

However, living in the era of active socio-cultural transformations, during the period of the formation of the information society, we again and again return to the work of V. Vernadsky, whose ideas, in our opinion, laid the foundation of the present stage of the scientific discourse. 
The subject of our interest is the scientific discourse as an intellectual, professional, legitimate, universal, historical discourse on science and its role in society. It is not synonymous with the words 'science', 'scientific communication', 'scientific community', 'socio-cultural environment of science,' etc., but combines all these phenomena into a single epistemological system [12]. Therefore, it is not surprising that some scientists specify what exactly they mean, when they use the word 'science'. For example, H. Patnem came to the conclusion that in the process of argumentation and mutual criticism, each scholar uses not only facts and empirical data, but also widely involves religious, political, philosophical views [13, p. 150]. Due to this, he believes that it is normal to take the word 'science' in quotation marks, thus emphasizing the limited methods of exact sciences in meeting modern social needs. These thoughts correlate with the conclusions of S. Krymskyi, who notes that in the era of globalization, the functions of science are universal, it penetrates into all cells of modern society from the sphere of production and consumption to the legitimization of theological disciplines [14, p. 148]. As a result, the boundaries of what can be called science become indistinct.

Taking into account the above-mentioned words, we believe that the introduction of the term 'scientific discourse' is a requirement of time, which is both methodological and socio-cultural in nature. It should be applied to the definition of the current stage of development of the scientific knowledge and to emphasize the unity of all forms of cognitive activity, which correspond to a single criterion - the search for truth.

The analysis of the essence of scientific discourse allows us to understand the doctrine of $\mathrm{V}$. Vernadsky on the scientific thought as a planetary phenomenon and to justify the assumption that this idea can be regarded as the starting point for the formation of modern scientific discourse and understanding of its essence. To solve this problem, we turn first to one of the main concepts of the scientific and philosophical concept of V. Vernadsky - the concept of the noosphere. As it is known, it was applied to the definition of the next stage of the evolution of nature, which, according to the concept of the thinker, must radically differ from the other active influence of the reasonably organized human activity on all natural processes. 'We can not consider the phenomenon of life from a scientific point of view... otherwise, as an expression of a single phenomenon, which exists continuously since the earliest geological epochs' [15, p. 298], since without living matter the earthly evolution would have stopped at the stage of architectonic landslides. However, the warmth of the Sun, the radioactivity of cosmic rays, the water and atmosphere existence 'made' the Earth to accumulate and convert the energy gain into the chemical and biological forms. However, according to the science, this procedure can only be performed by the living matter. Thus, the nature itself foresaw a direct connection of living and inanimate, intelligent and retarded due to its evolution, billions of years ago.

Despite this, the mass of the living matter has gradually become so critical that it has led to the emergence of thinking beings, the proportion of which, in the first stages, was small. But the mind changed everything. Guided by him, a person used and modified all the substance, and therefore humanity has become a significant geological force. Due to this, in front of him, 'his thoughts and work, arises the question about the restructuring of the biosphere with the respect of the interests of the free-thinking humanity as a one unit. This new state of the biosphere, to which we, without noticing it, are approaching, is the noosphere' $[15$, p. 550$]$, the field of intelligent, purposeful, deliberately organized human activity.

Table 1. Utilized by human [9, p. 138].

\begin{tabular}{|c|c|c|}
\hline & \multicolumn{2}{|c|}{ Utilized by human (\%) } \\
\hline Ancient times & 19 & 21,3 \\
\hline Till $18^{\text {th }}$ century & 25 & 29,2 \\
\hline
\end{tabular}




\begin{tabular}{|c|c|c|}
\hline $18^{\text {th }}$ century & 28 & 31,4 \\
\hline $19^{\text {th }}$ century & 50 & 56,1 \\
\hline $20^{\text {th }}$ century & 61 & 68,5 \\
\hline
\end{tabular}

Developing the hypothesis of the unity of man and nature, V. Vernadsky was far from the phantasmagoric conclusions of some of the representatives of the philosophy of cosmicism. The scientist noticed that the question of eternal life can not be solved only in the scientific formulation [16, 17], and moreover, should not refer exclusively to the planetary scale, since 'the eternity of life in the universe does not guarantee its eternity on our planet' [15, p. 120]. It is obvious that there is an anxiety about the future of mankind expressed here, indicating its fragile and, perhaps, temporary status. Only the awareness of the unity of man and space, the attraction of all the intellectual potential to preserve their harmonious development and mutual care can be a way that guarantees the long existence of civilization and culture.

As a result, V. Vernadsky formed the statement that the scientific thought and science play the prominent role as the driving element of the planetary geological force of social mankind. It should be mentioned that the scientist did not consider science as a way or the right to rule over nature, strongly rejecting the statement of Fr. Bacon on the identity of science and strength. In contrast, he noted that scientific knowledge, creating the noosphere (and thus destroying the harmony of the biosphere) should not conflict with existing geological and space processes, since it is not a random phenomenon, but expresses the result of long evolution.

Types of scientific continuity
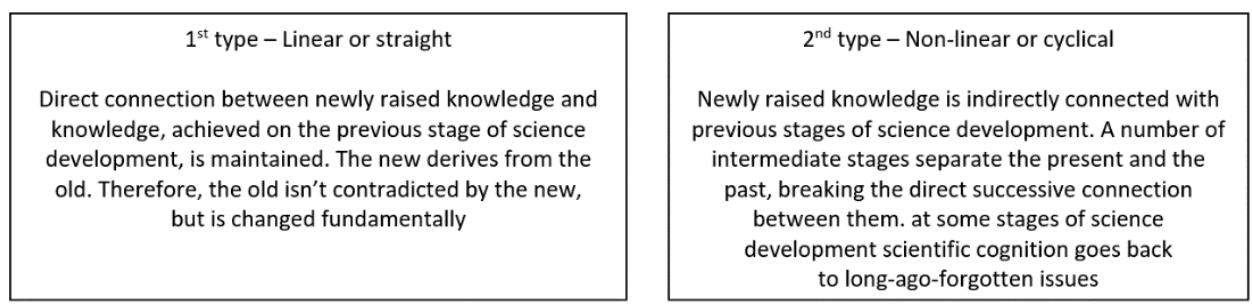

Fig. 3. Types of scientific continuity.

Realizing this, a person should use the natural intellectual capability in the most efficient way and carefully using it not only to meet the own needs, but also to develop various types of social activities and improve social relations.

Hence, the thinker actually delegated the responsibility for the future fate of the Earth, nature, humanity to the very person who, once started to transform the biosphere by the force of his own scientific thought, without the possibility to stop, slow down or bring the process back. On this occasion, he wrote: 'Scientific thought as a component of living matter in essence can not be a reverse phenomenon - it can stop in its motion, but, once appeared in the evolution of the biosphere, it becomes possible to develop in the course of time with no restrictions' [18, p. 13].

\section{Discussion}

Consequently, Vernadsky widely interpreted the phenomenon of science and the boundaries of its functioning. In his opinion, it is the science which allows us to comprehend the unity of all the aspects of human being and society, to realize the complementarity of various types of cognitive activity, and also to understand the role and significance of human civilization in a global, all-planetary context. Science, according to the researcher, it is 
nothing more than a manifestation of activity in human society, the totality of human thought.

It is difficult not to agree with these arguments, especially analyzing the current trends in the formation of scientific discourse. Today, every new thought, a new scientific result immediately becomes the subject of discussion not only in scientific, but also in philosophical, religious societies. In addition, the idea of introducing the so-called humanitarian expertise of scientific developments, whose purpose is the public control over the activities of scientists, can be accepted. Strange as it may appear, at the beginning of the 20th century people realized that 'the boundaries of a separate science, on which the scientific knowledge collapses, can not precisely determine the branch of the scientific thought of the researcher, exactly describe his work. The problems which interest him, increasingly do not fit into the limits of a particular science. We specialize not in science but in problems' [18, p. 94], the diversity of which generates a number of sciences. Along with this, according to the Vernadsky's forecasts, the role of humanitarian knowledge should grow, as there is no limit to the curiosity of the human person.

Therefore, despite the existence of some destructive and dangerous tendencies in the development of modern civilization, such an attachment of everyone who wishes to take part in the scientific discourse is a model of universal planetary science, a way of understanding the unity of mankind, of all living things and of space in general. This is what V. Vernadsky dreamed of when he wrote that this idea in the past was the driving force for the creativity of poets, writers, philosophers, the engine of life, the main task of state formations $[18$, p. 23$]$ ?

\section{Conclusions}

But today the situation is fundamentally changing, as the pace of development of the noosphere is determined by the growth of the scientific knowledge. Those transformations, took many centuries and now occur right in front of the eyes of one generation. This, obviously, concerns not only science but also society, human practice, mechanisms of organization of co-existence of people, as well as the systems of relations between man and nature.

The study confirms the hypothesis of the complementarity of the V. Vernadsky's doctrine of the scientific thought as a planetary phenomenon with modern approaches to understand and analyse the phenomenon of the scientific discourse. It turned out that the ways for finding the harmony of man and nature, man and space, intellect and evolution, found its further development in modern scientific and philosophical theories.

\section{References}

1. F. Fonseca, M. Marcinkowski, C. Davis, Cyber-human systems of thought and understanding. J. of the Assoc. for Inf. Scie. and Tech., 70, Issue 4, 402-411 (2019) DOI: $10.1002 /$ asi.24132

2. F. Caprotti, Critical research on eco-cities? A walk through the Sino-Singapore Tianjin Eco-City. Cities, 36, 10-17, China (2014) DOI: 10.1016/j.cities.2013.08.005.

3. V. Onoprienko, V.I. Vernadsky. Schools and followers. Kiev (2014)

4. G.P. Aksenov, Vernadsky. Life of outstanding people. Molodaya gvardiya, Moscow (2010)

5. M. Brenčič, Korespondenca med Vasilijem Vasilijevičem Nikitinom in Vladimirjem Ivanovičem Vernadskim. Geologija, 61/2, 229-238 (2018) 
6. L. Drotianko, S. Yahodzinskyi, Information environment as the intercultural communication space. Intern. Scie. Conf., SPbWORCE - 2016 «SMART City», 106 (2017) https://doi.org/10.1051/ matecconf/201710601006

7. V.A. Grachev, Scientific ideas of V. Vernadsky as the basis for a new worldview and sustainable development. The cent. of glob., 2, 143-157 (2015)

8. V.I. Vernadsky, Global Studies. Personalia, organizations, works. Encyclopedic reference book. Alpha, Moscow (2012)

9. I. Mochalov, V. Onoprienko, V.I. Vernadsky: Science. Philosophy. Person. Chapter 1. Science in historical and social contexts. Moscow (2008)

10. Z. Ivanova, O. Yudenkova, Biosphere Compatible Cities and Villages: How Can We Turn Them into Reality? Asian Social Science, 11, No. 1, 297-303 (2015)

11. S. Sokolovsky, Human 2.0 in the focus of anthropology. Sib. Hist. res., No. 3, 65-78 (2018)

12. S. Yahodzinskyi, Anthropomorphic. Networks as Representatives of Global Consciousness. Philosophy and Cosmology, 20, 146-153 (2018) 